[1]

1Service de Pneumologie, Hôpitaux Universitaires de Genève, Geneva, Switzerland.

2Programme Hypertension Pulmonaire, Hôpitaux Universitaires de Genève, Geneva, Switzerland.

${ }^{3}$ Service de Cardiologie, Hôpitaux Universitaires de Genève, Geneva, Switzerland.

${ }^{4}$ Unité de Cardiologie Pédiatrique, Hôpitaux Universitaires de Genève, Geneva, Switzerland.

\title{
Pulmonary hypertension in the elderly: a different disease?
}

\section{Introduction}

Pulmonary hypertension $(\mathrm{PH})$ is a haemodynamic syndrome defined by a mean pulmonary arterial pressure (mPAP) $>25 \mathrm{mmHg}$ determined by right heart catheterisation (RHC) [1, 2]. A lot of diseases fulfil this definition, but they differ widely between each other in respect to their pathophysiology, their haemodynamic characteristics, their clinical presentation, their natural prognosis and their potential therapeutic strategies. The current guidelines on $\mathrm{PH}$ diagnosis and management make the distinction between five groups of more than 200 causes of $\mathrm{PH}$ [2], but these diseases are very different from one another. In the current classification, the first group (group 1) represents a progressive vasculopathy leading to pre-capillary $\mathrm{PH}$ called pulmonary arterial hypertension (PAH), characterised by a characteristic small-calibre pulmonary artery remodelling, as a result of proliferation of endothelial and smooth muscle cells as well as medial hypertrophy. So, if we compare $\mathrm{PAH}$ (for example idiopathic $\mathrm{PAH}$ ) from $\mathrm{PH}$ due to valvular disease like mitral insufficiency (group 2.3) it is easy to understand that apart from the fact that mean pulmonary arterial pressure (mPAP) exceeds $25 \mathrm{mmHg}$ in both cases, these two entities have very different pathophysiological pathways. In the first case, there is a true pulmonary vasculopathy. In the second, $\mathrm{PH}$ is mainly related to the consequences of an increased hydrostatic pressure in the left atrium transmitted to the venous compartment of the pulmonary circulation and then back through the capillary bed. If the pathophysiology of these entities is different, the targets of their treatments are too. The main goal of $\mathrm{PAH}$ treatment consists in reducing pulmonary vascular resistance (PVR) with specific medication and, when appropriate, with specific treatment of the underlying disease as it is the case for associated-PAH (group 1.4). Alternatively, the management of $\mathrm{PH}$ related to a mitral regurgitation would be to improve the ventricular preload, diminish the ventricular afterload and, if necessary, to correct the anatomical anomaly.

$\mathrm{PAH}$ is then a subset of $\mathrm{PH}$ that is characterised by a specific pathophysiology, pathobiology and a specific haemodynamic pattern. During RHC, there is a pre-capillary PH (mPAP $\geqslant 25 \mathrm{mmHg}$; Pulmonary artery wedge pressure $(P A W P) \leqslant 15 \mathrm{mmHg}$ ) with an absolute increase in PVR (>3 WU). PAH can be either idiopathic or associated to other affections. The most common forms of associated-PAH are those related to drugs (anorexigens), connective tissue disease (scleroderma, lupus), infections (HIV, schistozomia), portal hypertension, congenital heart disease or chronic haemolytic anaemia. Pathologically, this group of affections is characterised by specific vascular changes (such as medial hypertrophy, endothelial proliferation and adventitial fibrosis) and by the alteration of specific functional molecular pathways. Among them, nitric oxide (NO), endothelin and prostacyclin
Cite as: Berra G, Noble S, Soccal P-M, et al. Pulmonary hypertension in the elderly: a different disease? Breathe 2016; 12: 43-49. 
are the currently recognised pathophysiological pathways, targeted by the currently available $\mathrm{PAH}$-specific treatments.

Unlike $\mathrm{PH}$, which is more frequent and mostly associated with heart or pulmonary diseases [3], $\mathrm{PAH}$ is a rare clinical condition whose incidence does not exceed three-five cases per 100000 inhabitants with an estimated prevalence of 15-50 per 100000 inhabitants [4]. As heart and pulmonary disease are rising in prevalence with ageing, prevalence of $\mathrm{PH}$ is also increasing. In a study by HOEPER et al. [5], risks factors associated with a diastolic dysfunction and then with an increased risk of $\mathrm{PH}$ are older age, obesity, atrial fibrillation, hypertension, coronary artery disease and diabetes (those pathologies increase in number with ageing) [5]. On the other hand, $\mathrm{PAH}$ is much more common among specific risk groups, such as patients with HIV infection (0.5\%), with portal hypertension ( $2 \%$ ) or with connective tissue diseases like scleroderma (8-16\%). Hence, the rarity of this condition contributes to the difficulty in establishing the diagnosis. Identification of these risk factors and associated conditions is therefore very important for screening. Recent data have shown that, while $\mathrm{PAH}$ was once thought of as affecting young adults, the mean age of patients with $\mathrm{PAH}$ now represents a growing proportion of older patients [6-11].

\section{PAH epidemiology: a changing picture}

The first published PAH registry described an affection that affects predominantly young women [12], with diagnosis occurring at a mean age of $<40$ years. According to the study, $<10 \%$ of patients were aged $>60$ years. Over the previous two decades, the frequency of diagnosis of any kind of $\mathrm{PH}$ among hospitalised patients aged 65 and over has been increasing. Since 1995 , this increase has been marked amongst patients aged $>85$ years. Between 1990 and 2002, the frequency in patients aged $>65$ year has multiplied by 3.4. The modern picture of $\mathrm{PAH}$ is changing with patient registries showing an increase of the mean age at PAH diagnosis (table 1) and an increase in the proportion of male patients. Data from both US and European registries confirm this increasing proportion of elderly patients at the time of diagnosis with $9-13.5 \%$ of patients aged $>70$ years; with the mean age at diagnosis at $\sim 50$ years. In one single-centre registry, the mean age of idiopathic $\mathrm{PAH}$ diagnosis was $55 \pm 16$ years and, in the recently published data from the Swiss registry, the mean age at $\mathrm{PAH}$ diagnosis $>60$ years and $56 \%$ were female [13]. Rather strikingly, another European registry [8] reported a median age of 71 years at diagnosis with $63 \%$ being aged $>65$ years. An ageing population in Western countries, an increase in life expectancy, together with the growing awareness of $\mathrm{PAH}$ and availability of potential treatments means that it is now not rare to see geriatric $\mathrm{PAH}$ patients.

The main issue of PAH diagnosis in the elderly is to discriminate potential pulmonary vascular disease from normal ageing and from the frequent causes of $\mathrm{PH}$ secondary to left heart failure or lung disease. Recently, a Dutch population-based study aimed to determine the prevalence of $\mathrm{PH}$ in the general population [14]; it found that prevalence of echocardiographic $\mathrm{PH}$ was $2.6 \%$. Prevalence was higher in older participants $(8.3 \%$ for $>85$ years

Table 1 Baseline characteristics of PAH at the time of diagnosis from different registries

\begin{tabular}{|c|c|c|c|c|c|c|c|c|}
\hline Registry & NIH [12] & $\begin{array}{c}\text { French } \\
\text { [10] }\end{array}$ & US [9] & $\begin{array}{c}\text { REVEAL } \\
\text { [11] }\end{array}$ & $\begin{array}{c}\text { UK/Ireland } \\
\text { [7] }\end{array}$ & $\begin{array}{l}\text { ASPIRE\# } \\
\text { [39] }\end{array}$ & $\begin{array}{c}\text { COMPERA } \\
{[8]}\end{array}$ & $\begin{array}{c}\text { Swiss } \\
\text { [13] }\end{array}$ \\
\hline Year & 1987 & 2006 & 2007 & 2010 & 2012 & 2012 & 2013 & 2015 \\
\hline Subjects n & 187 & 674 & 578 & 2525 & 482 & 175 & 587 & 171 \\
\hline Age years & $36 \pm 15$ & $50 \pm 15$ & $48 \pm 14$ & $50.1 \pm 14.4$ & $50.1 \pm 17.1$ & $55 \pm 16$ & $71 \pm 16$ & $60 \pm 15$ \\
\hline Women \% & 63 & 65.3 & 77 & 55.6 & 69.9 & 67 & 60.3 & 56 \\
\hline PAWP mmHg & १ & $8 \pm 3$ & $10 \pm 4$ & $9.1 \pm 3.5$ & $9.2 \pm 3.5$ & $10 \pm 3$ & $10 \pm 3$ & $12 \pm 7$ \\
\hline RAP mmHg & $9.7 \pm 6$ & $8 \pm 5$ & $11 \pm 7$ & $9.3 \pm 5.6$ & $10.1 \pm 6.0$ & $11 \pm 6$ & $8 \pm 5$ & $9 \pm 8$ \\
\hline $\mathrm{CI} L \mathrm{~min}^{-1} \mathrm{~m}^{-2}$ & $2.27 \pm 0.9$ & $2.50 \pm 0.8$ & $2.3 \pm 0.9$ & $2.4 \pm 0.8$ & $2.1 \pm 0.7$ & $2.3 \pm 0.8$ & $2.2 \pm 0.7$ & $2.6 \pm 0.8$ \\
\hline PVRi WU·m² & $26 \pm 14$ & $20.5 \pm 10.2$ & & $21.1 \pm 12.5$ & $23.1 \pm 10.3$ & & & \\
\hline
\end{tabular}

Data are expressed as mean \pm SD or $\%$ unless otherwise stated. mPAP: mean pulmonary artery pressure; PAWP: pulmonary artery wedge pressure; RAP: right atrial pressure; $\mathrm{Cl}$ : cardiac index; PVRi: pulmonary vascular resistance index; PVR: pulmonary vascular resistance. \#: Patients diagnosed with idiopathic PAH. १: PAWP was 8.69 \pm 3.9 in males and 7.94 \pm 3.7 in females. Data from ref [7-13, 39]. 
versus $0.8 \%$ in those aged $65-70$ years), and in those with underlying disorders (5.9\% for chronic obstruction pulmonary disease (COPD), 9.2\% for left ventricular systolic dysfunction versus $2.3 \%$ without; and $23.1 \%$ in severe left ventricular diastolic dysfunction versus $1.9 \%$ in normal or light diastolic dysfunction). Factors independently associated with higher systolic PAP estimated with echocardiography were older age, higher body mass index, left ventricular diastolic dysfunction, COPD and systemic hypertension. In another recent publication, the prevalence of subclinical mild diastolic dysfunction, detected using echocardiographic screening of the general population was one-third in 65-74-year-olds and more than half in those aged $>75$ years [15]. The same study showed that severe diastolic dysfunction occurs in $3 \%$ of this population.

\section{Age-related changes in heart and pulmonary circulation}

The effects of ageing on the respiratory system have been well studied [16]; in particular, a progressive decline in lung function seen with normal ageing [17], which is largely associated with an alteration of the system mechanics of the lungthorax and shows a decrease in static elastic recoil of the lung, an increase of chest-wall stiffness and a decrease in the respiratory muscles strength; loss of the total capillary lung volume has also been demonstrated. All these factors may lead to or facilitate PVR increase and subsequent development of $\mathrm{PH}$ even in the absence of clear associated disease.

On the other hand, it has been demonstrated that age-related vascular stiffening contributes to isolated systemic systolic hypertension in the elderly [18-21]. The pulmonary vascular bed could also be affected by this leading to pulmonary artery stiffening [22-24]. A decrease in left heart compliance has also been observed [18], which leads to progressive left ventricular diastolic dysfunction.

It is not surprising that systolic pulmonary artery pressure (sPAP) has shown a significant age-related increase of about $1 \mathrm{mmHg}$ per decade. Exercise measurements from healthy elderly subjects during exertion have also shown potentially significant increases of pulmonary artery pressure; sometimes with MPAP values frequently exceeding $30 \mathrm{mmHg}$. This has been an argument for abandoning the concept of exercise-induced $\mathrm{PH}$, which had previously been defined as mPAP $>30 \mathrm{mmHg}$ during exercise. The interesting and important question of the behaviour of pulmonary vascular circulation at exercise was indeed recently reassessed by HERVÉ et al. [25], who proposed new criteria for defining exercise-PH. It was demonstrated that the combination of mPAP $>30 \mathrm{mmHg}$ and total pulmonary resistance $($ TPR $=\mathrm{mPAP} /$ cardiac output $)>3 \mathrm{WU}$ lead to an excellent sensitivity and specificity for defining a pathological haemodynamic response of the pulmonary circulation during exercise (figure 1). Age-related physiological changes of both the cardiovascular and respiratory system should be considered if $\mathrm{PH}$ is suspected in the elderly. Potentially, normal ageing could lead to an overdiagnosis of $\mathrm{PH}$ or an underestimation of $\mathrm{PAH}$ in this population. Particularly, PAH may be suspected if an elderly patient presents haemodynamic and clinical alterations which are said to be "out of proportion to age" with elevated PVR and mPAP.

\section{Potential risk of misclassifying $\mathrm{PH}$ and its consequences}

The diagnosis of PAH is always difficult and even more in the elderly population. This is due to several reasons. Elderly patients are often affected by several pathologies at the same time, which makes more difficult to establish the accountability of a true involvement of pulmonary vasculature to $\mathrm{PH}$. For example, it is not uncommon to have a diabetic and hypertensive patient with some diastolic dysfunction and/or a respiratory disease. All these affections can lead to $\mathrm{PH}$. In the same patient, the presence of a true increase in pulmonary vascular resistance is still possible whatever its cause. The two are not mutually exclusive. On the other hand, $\mathrm{PH}$ is frequent in the elderly because of the high frequency of comorbidities leading to $\mathrm{PH}$, but the frequency of patients with a true increase in

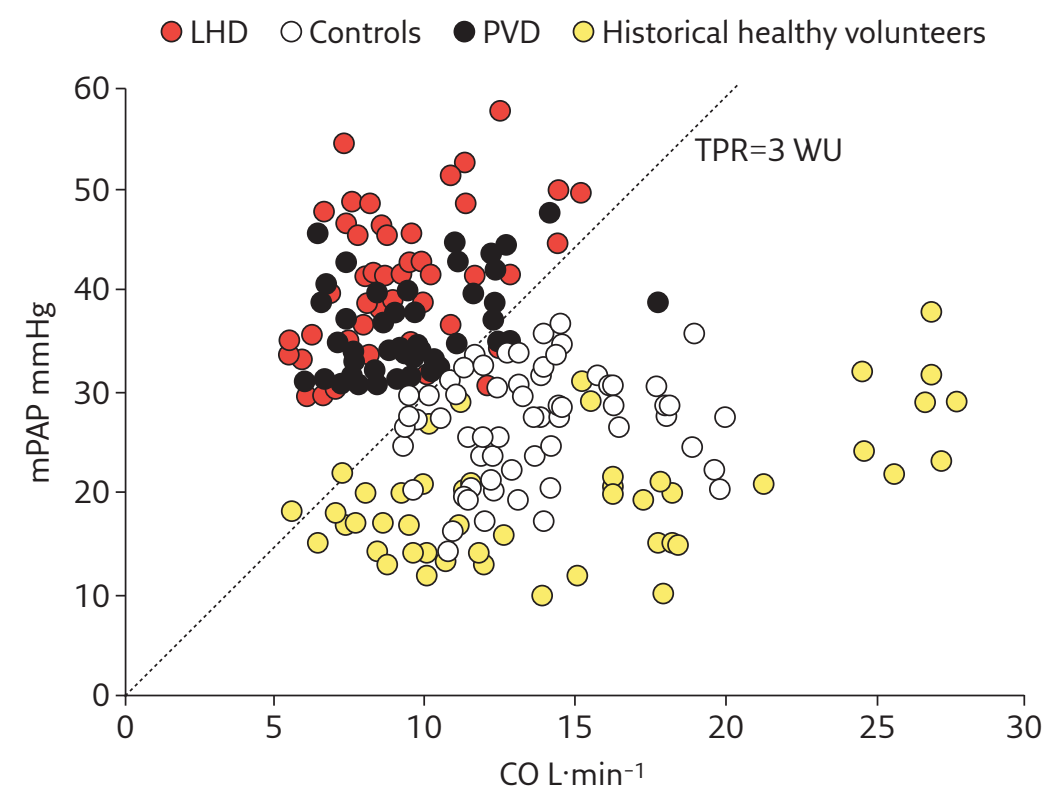

Figure 1 Relationship between exercise MPAP and cardiac output. Individual data points represent $M P A P$ and cardiac output reached at maximal exercise stratified by subjects with pulmonary vascular disease (PVD), left heart disease (LHD), control subjects and historical healthy volunteers. It can be seen that the total pulmonary resistance (TPR) line with a slope of 3 Wood units $(W U)$ differentiated the diseased (PVD and LHD) and non-diseased groups (controls and historical volunteers). Reproduced from [36] with permission from the publisher. 
pulmonary vasculature at the same time is much lower. Thus finding PAH among all PH is like looking for a needle in a haystack. Unfortunately, there are few clinical and simple predictors of $\mathrm{PAH}$. Except the presence of a connective tissue disease that is frequently associated with $\mathrm{PAH}$ in this group of age, other noninvasive parameters (left atrium size, signs of diastolic dysfunction) do not permit to definitively differentiate $\mathrm{PH}$ from $\mathrm{PAH}$ or a mixed disease [26]. Even haemodynamic evaluation by RHC may be equivocal and a full comprehensive haemodynamic workup is mandatory to increases its accuracy. In fact, group 1, 2 and 3 $\mathrm{PH}$ may look alike (table 2). Most of the patients included in the different national and international PAH registries benefit from the expertise of renowned centres that have most likely ruled out group 2 and group $3 \mathrm{PH}$ before confirming $\mathrm{PAH}$ diagnosis. The expertise involved constitutes the most robust argument in favour of the existence of PAH in the elderly. The converging conclusions of almost all international registries and expert centres reports are indeed convincing and $\mathrm{PAH}$ in the elderly must be considered as an emerging aspect of $\mathrm{PAH}$.

In the elderly population, the risk of $\mathrm{PH}$ misclassification is nevertheless particularly high and a consequence of it is the overestimation of true pulmonary vascular disease. Considering the fact that PAH has a specific pathophysiology and specific treatment, $\mathrm{PH}$ expert centres and $\mathrm{PH}$ specialists are facing new challenges and issues for the diagnosis and treatment of pulmonary vascular diseases in a growing elderly population. If diagnosis procedure is not precise and complete enough, mixing of the population of true $\mathrm{PAH}$ with other $\mathrm{PH}$ groups may be possible. This could have major consequences on therapeutic choices and armful consequences on both the patient and the overall PAH population. In fact, the evaluation of efficacy and safety of $\mathrm{PAH}$ specific treatment could be altered by inclusion of misdiagnosed patient with the potential risk of inappropriate conclusions on PAH-specific treatment efficacy or safety. As an example, it is well documented that PAH specific treatments should not be prescribed in group $2 \mathrm{PH}$. Indeed, $\mathrm{PAH}$-specific treatments have not been studied in patients of this age category, as it was the case for the paediatric population [27]. So they may be an increased risk of adverse effects of $\mathrm{PAH}$-specific treatment. The most recently published phase III randomised controlled trials dedicated to evaluation of new $\mathrm{PAH}$-specific treatment included patients with a mean age far below 50 years and $<20 \%$ of patients were aged $>65$ years [28]. So even if current international guidelines for the treatment of $\mathrm{PAH}$ do not makea distinction between the elderly and another age

Table 2 Comparison of clinical and hemodynamic parameters in series of patients with COPD - PH with or without associated disease (left heart disease, thromboembolic disease, obesity hypoventilation or sleep apnoea), HFpEF - PH and PAH

\begin{tabular}{|c|c|c|c|c|}
\hline & \multicolumn{2}{|c|}{ COPD-PH } & \multirow[t]{2}{*}{ HFpEF-PH } & \multirow[t]{2}{*}{ PAH } \\
\hline & $\begin{array}{c}\text { Without associated } \\
\text { disease }\end{array}$ & $\begin{array}{c}\text { With associated } \\
\text { disease }\end{array}$ & & \\
\hline Subjects n & 11 & 16 & 20 & 20 \\
\hline Age years & $67(63-68)$ & $61(56-68)$ & $71.3 \pm 7.8$ & $70.2 \pm 6.7$ \\
\hline BMI kg m-2 & $26(21-30)$ & $26(22-33)$ & $31 \pm 6.8$ & $28.2 \pm 3.2$ \\
\hline Women \% & & & 80 & 70 \\
\hline mPAP mmHg & $48(46-50)$ & $43(42-49)$ & $50.2 \pm 7.1$ & $50.2 \pm 9.5$ \\
\hline PAWP mmHg & $6.0(4.0-7.0)$ & $9.0(4.0-18.0)$ & $22.8 \pm 4.4$ & $9.6 \pm 3.1$ \\
\hline RAP mmHg & $7.0(5.0-9.0)$ & $5.0(3.0-9.7)$ & $14.8 \pm 4.9$ & $10.7 \pm 5.6$ \\
\hline TPG mmHg & & & $27.5 \pm 4.8$ & $40.5 \pm 8.8$ \\
\hline DPG mmHg & & & $6.3 \pm 6.2$ & $22.0 \pm 7.8$ \\
\hline $\mathrm{CI} \mathrm{L} \mathrm{min}-1 \cdot \mathrm{m}^{-2}$ & $2.3(1.8-2.5)$ & $2.8(1.9-3.8)$ & $2.5 \pm 0.5$ & $2.3 \pm 0.3$ \\
\hline TPR WU & $21.3(17.6-26.6)$ & $14.9(11.0-28.4)$ & & \\
\hline PVR WU & & & $6.3 \pm 2.1$ & $9.3 \pm 2.7$ \\
\hline
\end{tabular}


group, it is possible that $\mathrm{PH}$ expert centre may face unexpected adverse events in this more fragile population.

The situation may be even more complex as there is some evidence showing that group $3 \mathrm{PH}$ may in some cases harbour intrinsic increase in pulmonary vascular resistance that mimic $\mathrm{PAH}$. Indeed, CARLSON et al. [29] have recently shown that a subset of patients suffering from COPDrelated $\mathrm{PH}$, without identified cause of coexistent $\mathrm{PAH}$, presented similar vascular lesions to patients who died from PAH. Similarly, patients with group $2 \mathrm{PH}$ and established left ventricular dysfunction or heart failure with preserved ejection fraction (HFpEF) could also present some degree of pre-capillary component of $\mathrm{PH}$ added to the post-capillary contribution of heart dysfunction. It is important to consider that the general classification in the five groups of $\mathrm{PH}$ could then sometimes be considered as a simplification of a complex and intricate reality. And this may be even more the case in the elderly population.

Of course, the key investigation to precisely characterise the specific contribution of postcapillary and pre-capillary mechanisms is the right heart catheterisation. It's usually recommended that all patients suffering from a pulmonary disease or heart disease associated with what was previously called "out of proportion $\mathrm{PH}$ " should have further haemodynamic investigation to consider the potential diagnosis of mixed $\mathrm{PH}$ with an intrinsic increase of pulmonary vascular resistance. Moreover patients with an autoimmune context (connective tissue disease) or patients with anorexigen drug exposure could have the same screening, because the well-known association between these conditions and a significantly increased risk of PAH [30].

\section{RHC pitfalls in the elderly population}

Haemodynamic evaluation is the central procedure for diagnosis and characterisation of the $\mathrm{PH}$ group and this is also true in the elderly population. Here, the possible association of pulmonary disease, cardiac disease and pulmonary vascular disease in the same patient make the interpretation of haemodynamic profile more difficult and thus requires full attention. Despite being the gold standard diagnostic procedure, invasive haemodynamic evaluation presents potential pitfalls to be avoided. In evaluation of elderly patients and the mandatory elements for confirmation of $\mathrm{PAH}$, haemodynamic parameters assessed by $\mathrm{RHC}$ must be carefully examined and sometimes challenged. This is the case for mPAP $\geqslant 25 \mathrm{mmHg}$, which could be expected in one in 250 healthy subjects aged $\geqslant 50$ years, compared with only one in 5000 younger subjects [31]. Once PH is confirmed,
PAWP should be determined. This is a parameter assumed to be a surrogate marker for left ventricle end-diastolic pressure (LVEDP) and allows classification of $\mathrm{PH}$ as pre-capillary or post-capillary using a cut-off of $15 \mathrm{mmHg}$. In older patients, as prevalence of cardiac and pulmonary pathologies is particularly high, as previously discussed, PAWP might be less reliable. One study showed that more than half of the patients with $\mathrm{PH}$ and PAWP $<15 \mathrm{mmHg}$ had LVEDP $>15 \mathrm{mmHg}$ [32]. This implies that reliance on PAWP rather than LVEDP in patients with suspected elevated left filling pressure, which is frequent in the elderly [33], may result in a misdiagnosis of $\mathrm{PAH}$. It is therefore advisable to consider LVEDP measurement by left heart catheterisation in patients for whom HFpEF must be excluded or in patient with alteration of pulmonary function test and possible significant pressure changes during respiratory cycle that may overestimate PAWP. It should also be considered that mild diastolic dysfunction is common in older patients and this may result in ruling out PAH unduly. In these cases, pharmacological testing to assess the vascular reactivity may help to identify true PAH, but these procedures are not endorsed by current $\mathrm{PH}$ guidelines. In patients with an increased PAWP, the use of diastolic pulmonary vascular pressure gradient (DPG) is a classic way to distinguish patients with a true pre-capillary component in a post-capillary setting while NAEIJE et al. [34] have nicely shown that transpulmonary gradient (TPG) is not devoid of limitations. It is also particularly true in the older patients, in which TPG has to be interpreted with caution due to vascular stiffness that might induce an overestimation of this parameter. Differentiation between pre-capillary and postcapillary $\mathrm{PH}$ is then not straightforward even with $\mathrm{RHC}$, particularly in the elderly population. Thus, elderly patients with suspicion of PAH should be addressed to an expert $\mathrm{PH}$ centre to benefit from a precise haemodynamic evaluation and an appropriate diagnosis. In these centres, after selection of patients, extensive haemodynamic profiles must be established with both right and left heart catheterisation.

To help distinguish between true increase in vascular resistance and post-capillary physiopathology, a multi-points analysis of cardiac output-mPAP relation seems to be effective [35]. This aspect again underlines the potential utility of exercise haemodynamics and fluid challenge in determining true pulmonary vascular resistance, and in unmasking an HFpEF respectively (figure 2). In contrast with a single measurement at rest of MPAP, PAWP, cardiac output and derived PVR, combination of rest and exercise measures permit to give an accurate insight of the real resistive properties of the pulmonary circulation (figure 3) [36]. In addition to exercise procedure, HFpEF might also be unmasked by fluid challenge in patients with normal PAWP and suspected 


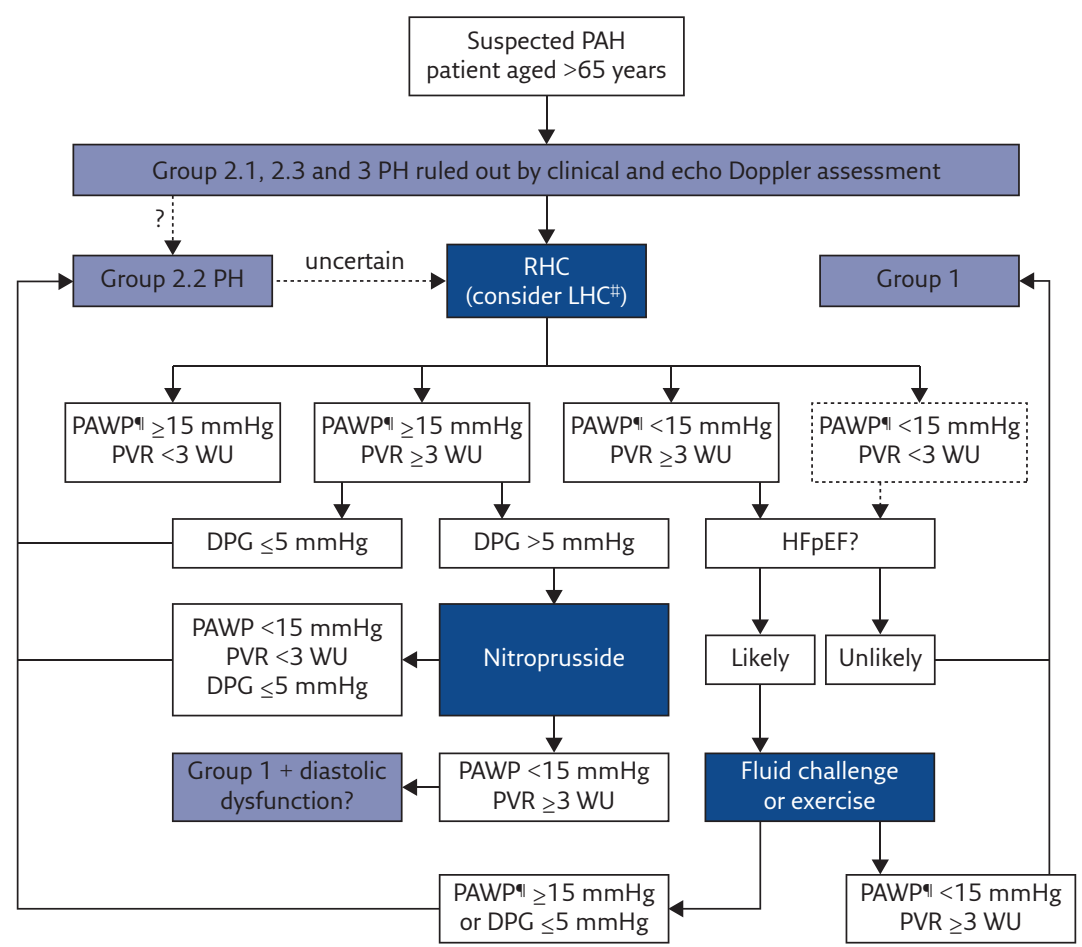

Figure 2 Algorithm for haemodynamic evaluation in the elderly. Clinical groups refer to the current international classification of PH [1]. RHC: right heart catheterisation; PAWP: pulmonary artery wedge pressure; PVR: pulmonary vascular resistance; DPG: diastolic pulmonary gradient; $L H C$ : left heart catheterisation; HFpEF: heart failure with preserved ejection fraction. 9: PAWP or left ventricle end-diastolic pressure (LVEDP). \#: LVEDP measurement by left heart catheterisation ( $L H C$ ) should be discussed prior to and performed along with RHC. It might be a reasonable option if the patient presents several risk factors for diastolic dysfunction in addition to age, including obesity, metabolic syndrome, diabetes, hypertension, CAD. In selected patients with normal PAWP and PVR (dotted box), exercise or fluid challenge might be discussed in order to unmasked left heart disease or early pulmonary vascular disease. Reproduced from [35] with permission from the publisher. patients in the different groups of $\mathrm{PH}$. In fact, it seems to be coherent that haemodynamic evaluation could also be performed during exercise, a condition prone to induce most of the symptoms developed in $\mathrm{PH}$. It also noteworthy that the validation of a reliable non-invasive device that allow accurate determination of cardiac output changes during exercise is desirable in this context $[37,38]$.

\section{Conclusion}

$\mathrm{PH}$ in the elderly is not different than in other age group. However, the distinction between disease and normal ageing and between $\mathrm{PH}$ and $\mathrm{PAH}$ may be more difficult. In fact, the many comorbidities that could lead to $\mathrm{PH}$ make its diagnostic classification much more difficult and the identification of patients with a true vascular disease even more challenging. Elderly $\mathrm{PAH}$ patients suffer from severe pulmonary vascular disease with a poor survival rate and should be accurately diagnosed before introduction of $\mathrm{PAH}$-specific drug therapy. In addition, age-related physiological changes should be considered if $\mathrm{PH}$ is suspected in the elderly because the normal process of ageing has the potential to lead to an overdiagnosis of $\mathrm{PH}$ or an underestimation of $\mathrm{PAH}$. Every patient with suspected $\mathrm{PAH}$ should be referred to an expert centre to benefit from complete investigations and comprehensive haemodynamic evaluation. This is true for all patients but especially for the elderly. The modern available $\mathrm{PAH}$-specific treatment may be differently tolerated in elderly patients. However, one should remember that $\mathrm{PAH}$ is a devastating disease that should be appropriately treated with ambitious goals.

diastolic dysfunction. To this purpose, we rece proposed an algorithm of interpretation of haemodynamic investigations to properly classify
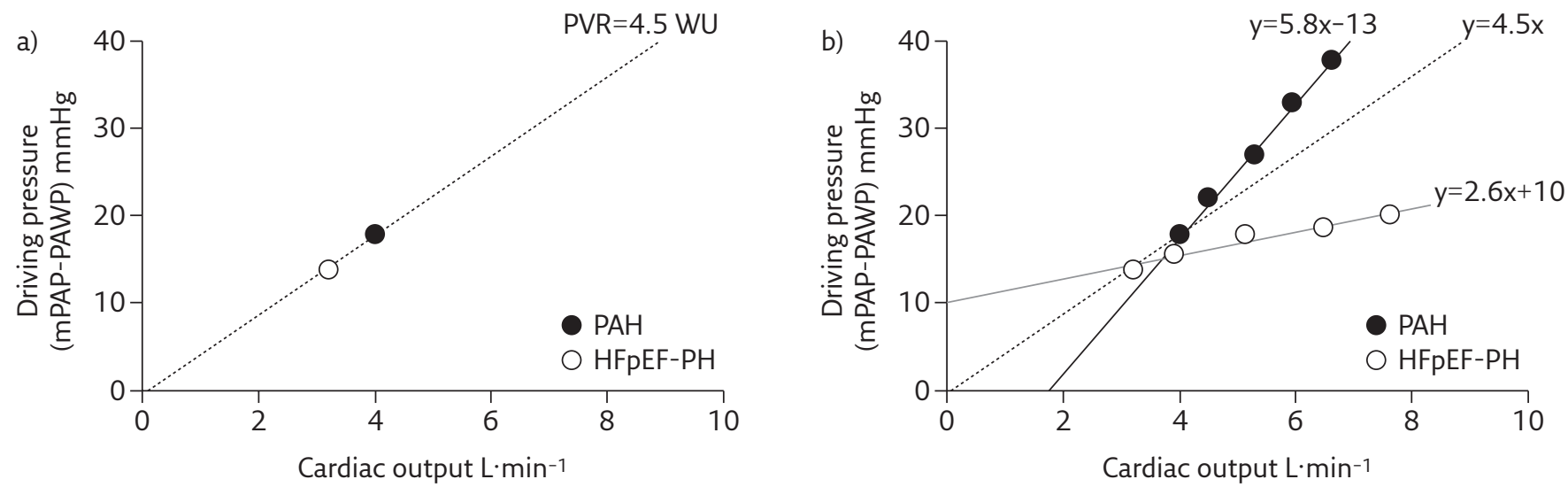

Figure 3 Example of resting haemodynamic characteristics of two different patients with PAH (black dots) and HFpEF-PH (open dots). PAH patient: $m P A P$ $30 \mathrm{mmHg}$, PAWP $12 \mathrm{mmHg}$, cardiac output $4 \mathrm{~L} \cdot \mathrm{min}^{-1} ;$ HFpEF-PH patient: $\mathrm{mPAP} 29 \mathrm{mmHg}$, PAWP $14 \mathrm{mmHg}$, cardiac output $3.3 \mathrm{~L} \cdot \mathrm{min} \mathrm{n}^{-1}$. Note that both patients operating point of the pressure-flow relationship are placed on the same PVR regression line. b) Subsequent hemodynamic values are obtained during supine step increase exercise with leg ergometer placed on the RHC table. The regression lines obtained from experimental data are very different. For PAH, the regression line (black line) intercept is negative with a steeper slope (5.8) compared with the HFpEF-PH regression line (grey line) whose intercept is positive (slope 2.6), revealing completely different resistive properties of the pulmonary vasculature. Reproduced from [35] with permission from the publisher. 


\section{Conflict of interest}

Disclosures can be found alongside the online version of this article at breathe.ersjournals.com

\section{References}

1. D’Alonzo GE, Barst RJ, Ayres SM, et al. Survival in patients with primary $\mathrm{PH}$. Results from a national prospective registry. Ann Intern Med 1991; 115: 343-349.

2. Galiè N, Hoeper M, Humbert $M$, et al. Guidelines for the diagnosis and treatment of PH. Eur Heart J 2009; 30: 24932492.7.

3. Lam CS, Roger VL, Rodeheffer RJ, et al. Pulmonary hypertension in heart failure with preserved ejection fraction: a community-based study. J Am Coll Cardiol 2009; 53: 1119-1126.

4. Peacock AJ, Murphy NF, McMurray JJ, et al. An epidemiological study of pulmonary arterial hypertension. Eur Respir J 2007; 30: 104-109.

5. Hoeper MM, et al. Diagnosis, assessment, and treatment of non-pulmonary arterial hypertension $\mathrm{PH}$. J Am Coll Cardiol 2009; 54: S85-S96.

6. Foley RJ, Wilcox D, Walsh SJ, et al. Survival of geriatric idiopathic pulmonary arterial hypertension patients. Conn Med 2011; 75: 11-15.

7. Ling Y, Johnson MK, Kiely DG, et al. Changing Demographics, Epidemiology, and Survival of Incident Pulmonary Arterial Hypertension Results from the Pulmonary Hypertension Registry of the United Kingdom and Ireland. Am J Respir Crit Care Med 2012; 186: 790-796.

8. Hoeper MM, Huscher D, Ghofrani HA, et al. Elderly patients diagnosed with idiopathic pulmonary arterial hypertension: Results from the COMPERA registry. Int J Cardiol 2012. Nov 16. pii: S0167-5273(12)01401-5.

9. Frost AE, Badesch DB, Barst RJ, et al. The Changing Picture of Patients With Pulmonary Arterial Hypertension in the United States, How REVEAL Differs From Historic and Non-US Contemporary Registries. Chest 2011; 139: 128-137.

10. Humbert M, Sitbon O, Chaouat A, et al. Pulmonary arterial hypertension in France: results from a national registry. Am J Respir Crit Care Med 2006; 173: 1023-1030.

11. Badesch DB, Raskob GE, Greg Elliott C, et al. Pulmonary Arterial Hypertension, Baseline Characteristics From the REVEAL Registry. Chest 2010; 137: 376-387.

12. Rich S, Dantzker DR, Ayres SM, et al. Primary PH. A national prospective study. Ann Intern Med 1987; 107: 216-223.

13. Mueller-Mottet S, Stricker H, Domeninghetti G, et al. Long-Term Data from the Swiss Pulmonary Hypertension Registry. Respiration 2015; 89: 127-140.

14. Moreira EM, Gall H, Leening MJG, et al. Prevalence of Pulmonary Hypertension in the General Population: The Rotterdam Study. PLoS One 2015; 10: e0130072.

15. Redfield MM, Jacobsen SJ, Burnett JC Jr, et al. Burden of systolic and diastolic ventricular dysfunction in the community: appreciating the scope of the heart failure epidemic. JAMA 2003; 289: 194-202.

16. Janssens JP, Pache JC, Nicod LP. Physiological changes in respiratory function associated with ageing. Eur RespirJ 1999; 13: 197-205.

17. Knudson RJ, Slatin RC, Lebowitz MD, et al. The maximal expiratory flow \pm volume curve: normal stand-ards, variability, effects of age. Am Rev Respir Dis 1976; 113: 587599.

18. Chen $\mathrm{CH}$, Nakayama M, Nevo E, et al. Coupled systolic-ventricular and vascular stiffening with age: implications for pressure regulation and cardiac reserve in the elderly. $J$ Am Coll Cardiol 1998; 32: 1221-1227.

19. Perry HM Jr, Davis BR, Price TR, et al. Effect of treating isolated systolic hypertension on the risk of developing various types and subtypes of stroke: the Systolic Hypertension in the Elderly Program (SHEP). JAMA 2000; 284: 465-471.
20. Mitchell GF, Parise $H$, Benjamin EJ, et al. Changes in arterial stiffness and wave reflection with advancing age in healthy men and women: the Framingham Heart Study. Hypertension 2004; 43: 1239-1245.

21. Redfield MM, Jacobsen SJ, Borlaug BA, et al. Age- and gender-related ventricular-vascular stiffening: a community-based study. Circulation 2005; 112: 2254-2262.

22. Hosoda Y, Kawano K, Yamasawa F, et al. Age-dependent changes of collagen and elastin content in human aorta and pulmonary artery. Angiology 1984; 35: 615-621.

23. Farrar JF, Blomfield J, Reye RD. The structure and composition of the maturing pulmonary circulation. J Pathol Bacteriol 1965; 90: 83-96.

24. Mackay EH, Banks J, Sykes B, et al. Structural basis for the changing physical properties of human pulmonary vessels with age. Thorax 1978; 33: 335-344.

25. Herve P, Lau EM, Sitbon O, et al. Criteria for diagnosis of exercise PH. Eur Respir J 2015; 46: 728-737.

26. Pugh ME, Sivarajan L, Wang L, et al. Causes of $\mathrm{PH}$ in the elderly. Chest 2014; 146: 159-166.

27. Lador F, Sekarski N, Beghetti M. Treating PH in pediatrics. Expert Opin Pharmacother 2015; 16: 711-726.

28. Pulido T, Adzerikho I, Channick RN, et al. Macitentan and Morbidity and Mortality in Pulmonary Arterial Hypertension. N Engl J Med 2013; 369: 809-818.

29. Carlsen J, Hasseriis Andersen K, Boesgaard S, et al. Pulmonary arterial lesions in explanted lungs after transplantation correlate with severity of $\mathrm{PH}$ in chronic obstructive pulmonary disease. J Heart Lung Transplant 2013; 32: 347-354.

30. Abenhaim L, Moride Y, Brenot F, et al. Appetite-suppressant drugs and the risk of primary $\mathrm{PH}$. International Primary Pulmonary Hypertension Study Group. N EnglJ Med 1996; 335: 609-616.

31. Kovacs G, Berghold A, Scheidl S, et al. Pulmonary arterial pressure during rest and exercise in healthy subjects: a systematic review. Eur Respir / 2009; 34: 888-894.

32. Mahjoub H, Levy F, Cassol M, et al. Effects of age on pulmonary artery systolic pressure at rest and during exercise in normal adults. EurJ Echocardiogr 2009; 10: 635-640.

33. Savale L, Chaumais MC, Cottin V, et al. Pulmonary hypertension associated with benfluorex exposure. Eur Respir J 2012; 40: 1164-1172.

34. Naeije R, Vachiery JL, Yerly $\mathrm{P}$, et al. The transpulmonary pressure gradient for the diagnosis of pulmonary vascular disease. Eur Respir J 2013; 41: 217-223.

35. Lador F, Herve P. A practical approach of $\mathrm{PH}$ in the elderly. Semin Respir Crit Care Med 2013; 34: 654-664

36. Herve $\mathrm{P}$, et al. Criteria for diagnosis of exercise $\mathrm{PH}$. Eur Respir J 2015; 46: 728-737.

37. Lador F, Hervé P, Bringard A, et al. Non-Invasive Determination of Cardiac Output in Pre-Capillary Pulmonary Hypertension. PLoS One 10: e0134221.

38. Rich JD, Archer SL, Rich S. Noninvasive cardiac output measurements in patients with PH. Eur Respir J 2013; 42: 125-133

39. Hurdman J, Condliffe R, Elliot CA, et al. Pulmonary hypertension in COPD: results from the ASPIRE Registry. Eur Respir J 2013; 41: 1292-1301.

40. Chaouat A, Bugnet AS, Kadaoui N, et al. Severe Pulmonary Hypertension and Chronic Obstructive Pulmonary Disease. Am J Respir Crit Care Med 2005; 172: 189-194.

41. Adir Y, Humbert M, Sitbon O, et al. Out-of-Proportion Pulmonary Hypertension and Heart Failure with Preserved Ejection Fraction. Respiration 2013; 85: 471-477. 